\title{
Intersection of a ruled surface with a free-form surface
}

\author{
Xiaoping Wang • Weizhong Zhang $\cdot$ Liyan Zhang
}

Published online: 11 October 2007

(C) Springer Science + Business Media, LLC 2007

Erratum to: Numer Algor, published online: 14 August 2007 DOI 10.1007/s11075-007-9118-y

Due to conversion problems, Figs. 2, 3, 4, 5 and 6 in the paper by these authors have been misrepresented. They are hereby presented in proper fashion.

Fig. 2 Piecewise tracing one connected component, where $L_{i}$ are critical points and $P_{i}$ are starting points, $i=1,2$

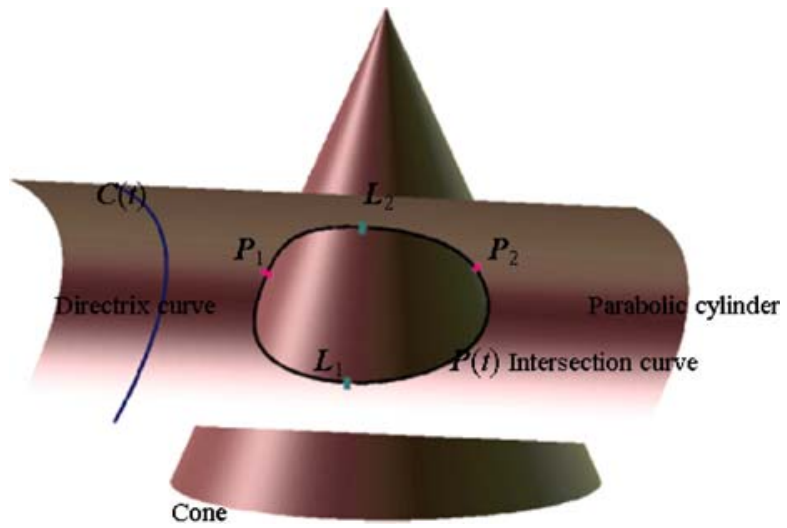

The online version of the original article can be found at http://dx.doi.org/10.1007/s11075-007-9118-y.

X. Wang $(\bowtie) \cdot$ L. Zhang

Research Center of CAD/CAM Engineering, Nanjing University of Aeronautics and Astronautics, Nanjing 210016, People's Republic of China e-mail: harayano@hotmail.com

W. Zhang

College of Information Engineering, Qingdao University, Qingdao 266071,

People's Republic of China 
Fig. 3 Open intersection curve, where point $P_{0}$ is starting point for tracing

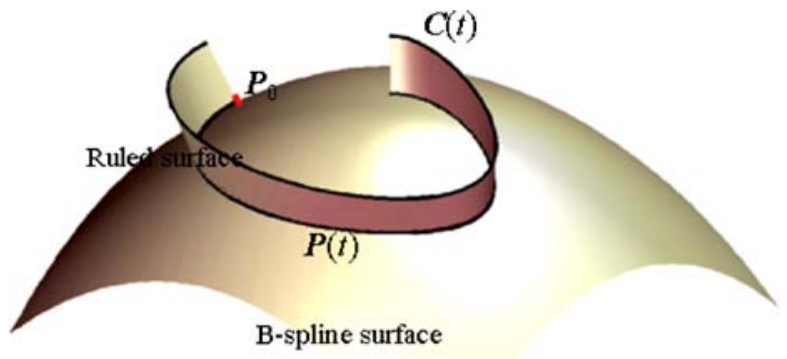

Fig. 4 Closed intersection curve, where point $P_{0}$ is starting point for tracing

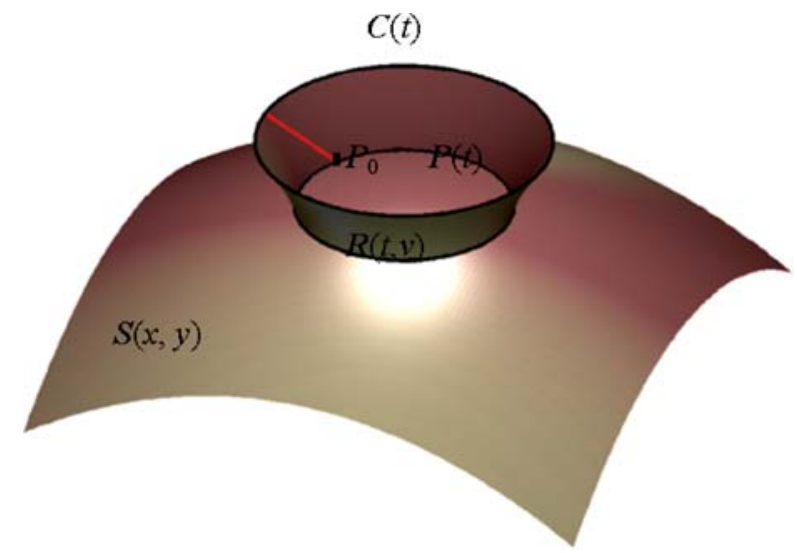

Fig. 5 Intersection of two cones, where point $P_{0}$ is starting point for tracing

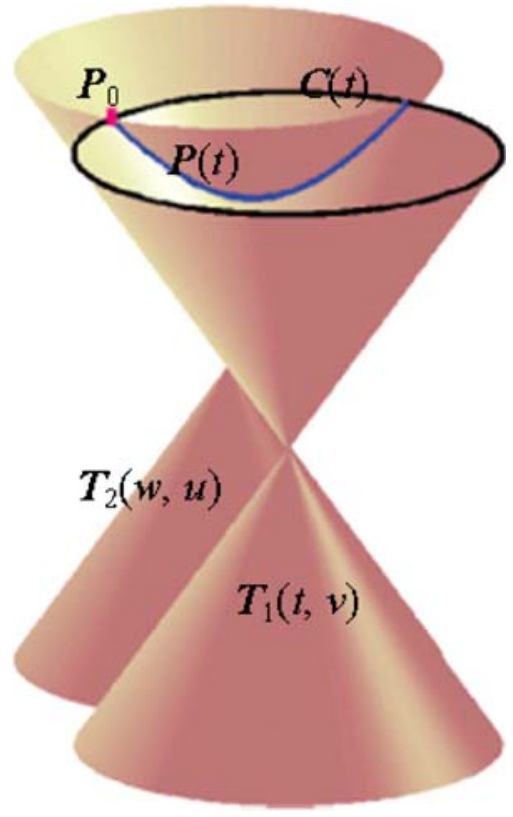


Fig. 6 Intersection curve composed of two unconnected components, where $P_{i}$ is starting points, $i=1,2$

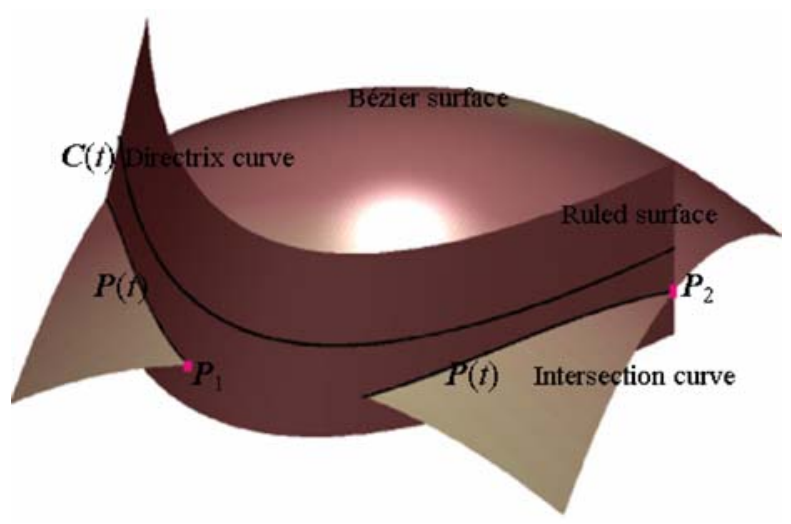

